\title{
Evaluation of Indonesian Traditional Herbal Medicine Ontology Quality
}

\author{
Kridanto Surendro, Farrel Yodihartomo, and Lenny Putri Yulianti \\ School of Electrical Engineering \& Informatics \\ Institut Teknologi Bandung, Indonesia \\ \{endro, farrell, lenny\}@ informatika.org
}

\begin{abstract}
Research and explorations about the benefit of Traditional Medicine (TM) Knowledge are still remained recently. Due to its benefits and widespread ancient practices, the information contained within the knowledge of traditional medicine has potential to be taken in studies that support modern healing methods. This research is focused on the evaluation of Traditional Medicine knowledge ontology which is developed for the purpose to distinctively solve encountered problems in traditional way which are still in use by native people such as healing wound, curing diseases, and so on. A quantitative approach is conducted by using reliable measurement and evaluation methods in order to acquire a valid evaluation result of the ontology. The result of this research indicates the reliability of the developed ontology in storing provided knowledge as a knowledge base according to the measurement evaluation and validation.
\end{abstract}

Keywords: Ontology; Traditional Herbal Medicine; Indigenous Knowledge; Evaluation Model

\section{Introduction}

Indigenous knowledge (IK) has been used by indigenous people since a long time ago. This knowledge helps those people developing their tribe as their culture and way of life are influenced by environment. Indigenous people live in a group through generations and interact closely with nature which simultaneously developed knowledge in a particular form that is not presented in a codified form [1].

The indigenous knowledge has always been a subordinate position to western science because they have been considered more primitive and lack of scientific evidence [2]. In the most literature, to make a rational judgment about other knowledge system (e.g. indigenous knowledge), both of indigenous and western knowledge system is significantly different. Despite, the IK is useful in many aspects to solve problems. In eastern of Uganda, IK of traditional medicines and healing methods have been accumulated and transmitted orally from generation to generation by diverse tribes. Many traditional medicine practitioner or healer lack of formal education but they are capable of healing patients using sustainable biomedicine and traditional techniques $[3,4]$.

Similarly, Nigeria has been encouraging traditional healer by integrating them into the staterun national health services as health care providers [3]. Another example of successful of traditional medical practice can be found in Indonesia where they consume jamu as a complementary and alternative medicine [5]. Clearly, each tribe have their own uniqueness and the indigenous knowledge has been developed for centuries by people that have survived in particular geographical area [6]. They believe in the outcomes of their practices even they do not possess the reason of how such outcomes come about.

Medical knowledges are also found in India. Four tribes are live in isolated area which practically no organized medical access. Those tribes have a wide IK of utilizing diverse medicinal plants into native medicines for particular ailments. Based on that situation, the idea of reducing the cost of curing various disease, by practicing their own treatment method, have been shared widely among tribe to tribe, member to member [7].

In order to understand about the medical IK itself, ontology has taken into account as an approach to codify that kind of knowledge [8]. By acknowledging of conceptual relationship and formal representation of IK, it is possible to gain a logical perspective from people who require

Received: August $15^{\text {th }}, 2019$. Accepted: March $5^{\text {th }}, 2020$

DOI: 10.15676/ijeei.2020.12.1.6 
accesses to medical IK in the first place. Ontology is a statement about knowledge representation that provides "explicit conceptualization specifications" [9]. Ontology helps in sharing knowledge and as a model of knowledge in technology-enhanced learning, training and knowledge management (e.g. 9, 10, 11).

Unfortunately, because it has syntactic or semantic weaknesses [12], many ontologies are considered not to have adequate quality [13]. Because the structure and functionality of ontologies are different, the software quality evaluation model cannot be applied to assess the quality of an ontology directly [14]. Most ontologies contain a vocabulary that represents the concepts of a specific domain as classes, attributes as properties of the objects and classes, and relationships between the classes as relations. Therefore, both qualitative and quantitative measures are used to assess the relationship between various factors and ontological attributes. Zhu [14] suggests ways to assess ontologies by evaluating their quality. The metrics are well defined for the vocabulary, where several parameters are measured quantitatively for qualitative measurement components. Ontology quality evaluation method approaches can be in the form of assessment metrics where evaluation of ontology criteria is carried out as a whole until the individual assessment forms that evaluate ontologies only use a single criterion $[15,16,17]$.

Since the traditional knowledge of healing is effective and contains coherency between the anecdotal reality and the scientific result, this should be supported by a well-structured knowledge base to guarantee its quality and usefulness. Due to that statement, this research is conducted to evaluate the quality of developed traditional medicine knowledge ontology by applying qualitative approach of evaluation and measurement.

\section{Literature Review}

\section{A. Indigenous Knowledge Perspective in Traditional Medicine}

Knowledge has been widely defined by researchers and have various meanings. A definition of the knowledge itself is selected from Wiig [18] who defined knowledge as the understandings, and practical know-how that people possess. This knowledge is commonly classified to tacit and explicit knowledge [19]. Knowledge is possibly being valuable when it is acquired through reliable methods and those with the knowledge are more trustworthy [20].

Indigenous Knowledge is a particular traditional knowledge which has been developed within a specific condition by local people in a geographic area [21]. Native people, which possess the IK of their tribe, realize that the knowledge is changing overtime and they concern the method of people interacting with one another with the shifting value posed threat to the spread of indigenous way of life from elders to youth. Whereas, they applied IK as a central to Indigenous culture and way to relate human with the environment [22].

\section{B. Traditional Medicine Knowledge in OWL Representation}

Knowledge of traditional medicine (TM) has been passed through generations from the elders to the young generation. By the mean of practices and informal documentation, this knowledge is preserved within the tribe. Since its form has limitation to be represented in traditional way, a number of approaches has been taken into account to obtain its semantic form [23, 24, 25]. One of the widely used with respect to Semantic Web form is The World Wide Web Consortium Web Ontology Language (OWL). Semantic Web was developed as a group of methods and technologies which allow machines to understand the meaning of information on the World Wide Web (WWW) and today it is used to represent knowledge about the world. Ontologies generally describe classes, attributes, individuals, and relations. [26].

Since the former development of ontology has limitation in reusability, Modular Ontology (OntoMod) offers an easiness with respect to scale manage and reuse [27]. Evaluation of this modularity of ontology should be taken into account to cater this research objective as a reason to gain insight for applying improvements. 


\section{Ontology Quality of $O W L$}

Evaluating OntoMod with specific ontology topics can be done by differentiate the quality model of the ontology standard with the results of the verification of the proposed model. This helps this research in measuring the quality itself by adopting Kumar's OntoMod Evaluation Standard as a compliance reference which contain formulated, defined, and validated metrics suite for quality assessment of modular ontology through prototype [27]. The OntoMod metrics suite is purposed to measure the structural and behavior quality of an ontology. OntoMod Quality can be measured through several aspects. Those following subsection explain each measurement components.

\section{1) Size and Appropriateness of module size}

The number of entities in a module will represent a measure of modularity ontology. For each module $|\mathrm{M}|$ consists of the sum of the number of class $|\mathrm{C}|$, object properties $|\mathrm{OP}|$, data properties $|\mathrm{DP}|$, and individual $|\mathrm{I}|$. Thus, the size is computed as follows [28]:

$$
|\mathrm{M}|=|\mathrm{C}|+|\mathrm{OP}|+|\mathrm{DP}|+|\mathrm{I}|
$$

To ensure the size of an ontology, it is proposed to measure the appropriateness value which depends on the number of axioms in the module $\left(A_{x}\right)$ and has range between 0 and 1 , where the optimal size has a value of 1 . Since its principle to define an ideal of axiom value at 250 for an ontology, the appropriateness equation is defined

$$
\text { Appropriate }(\mathrm{Ax})=\frac{1}{2}-\frac{1}{2} \cos \left(\mathrm{Ax} \cdot \frac{\pi}{250}\right)
$$

\section{2) Cohesion \& Coupling}

Cohesion means connectivity between entities in a module. To measure cohesion, we use the following formula which is defined in [27], [28].

$$
\text { Cohesion }(M)=\left\{\sum_{C_{i} \in M} \sum_{C_{i} \in M} \frac{S R\left(c_{i}, c_{j}\right)}{|M|(|M|-1)} \text { if }|M|>1\right.
$$

where $|M|$ represents the number of entities in a module and $|M|(|M|-1)$ states the number of possible relationships between entities. A farness measure is used to calculate the strength of the relationship (SR) for each entity.

$$
\operatorname{SR}\left(C_{i}, C_{j}\right)=\left\{\begin{array}{cc}
\frac{1}{\text { farness( }(\mathrm{i})} & \text { if relations exist between } C_{i} \text { and } C_{j} \\
0 & \text { otherwise }
\end{array}\right.
$$

According to the mentioned formula of cohesion, if the value of cohesion is high then it shows that connection between entities is high.

On the other hand, Coupling has been defined as a degree of interdependence of a module. Entities in a module will have a strong relationship if the coupling value is high. To compute the coupling value, Khan [28] has defined this formula:

$$
\operatorname{Coupling}\left(\mathrm{M}_{\mathrm{i}}\right)=\left\{\begin{array}{cc}
\sum_{\mathrm{i}=0}^{\mathrm{n}} \sum_{\substack{\mathrm{j}=0 \\
\mathrm{i} \neq 0}}^{\mathrm{n}} \frac{\mathrm{NEL}_{\mathrm{M}_{\mathrm{i}}, \mathrm{M}_{\mathrm{j}}}}{\left|\mathrm{M}_{\mathrm{i}}\right|\left|\mathrm{M}_{\mathrm{j}}\right|} \mathrm{NEL}_{\mathrm{M}_{\mathrm{i}} \mathrm{M}_{\mathrm{j}}}>0 \\
0 & \text { otherwise }
\end{array},\right.
$$

where $\mathrm{NEL}_{\mathrm{Mi}, \mathrm{Mj}}$ stands for Number of External Link between a module $\mathrm{M}_{\mathrm{i}}$ and $\mathrm{M}_{\mathrm{j}}$ in a system.

\section{3) Complexity Metrics}

Understanding the complexity of ontologies can be used to handle large ontologies. The lower the complexity, the better the quality of the ontology produced. According to Yang [29], measuring the complexity of an ontology can be done based on the concept \& hierarchy of concepts, ratios, and correlations between links and classes. Complexity metrics of ontology can be computed through ComplexOnto which is formulated in [27] as following:

$$
\text { ComplexOnto }=\sum_{i=1}^{4} w_{i} \times \text { metric }_{i}
$$


where

metric $=\{L D, L C, L R, C C\}$ and $\sum_{i=1}^{4} w_{i}=1$

earn a full weight proportion, it is assigned the weight value for each metric is 0.25 and the metrici consists of [27]:

i. Link density (LD) is the ratio of number of non-subclass links to the maximum possible number of links in an ontology where

$\mathrm{LD}=\frac{|O P+D P|}{\frac{n}{2} C}, \frac{n}{2} C$ is the maximum count of possible links and $\mathrm{n}$ stands for the number of class.

ii. Links per concept (LC) is the ratio of total number of links to the number of concepts where $\mathrm{LC}=\frac{|O P+D P|}{n}$

iii. Link richness is defined as the ratio of non-subclass links to the total number of links, where $\mathrm{LR}=\frac{|O P+D P|}{|O P+| D P|+| S C \mid}$ and $\mathrm{SC}$ is the number of subclass axiom

iv. Cyclomatic Complexity $(\mathrm{CC})=(|O P|+|D P|+|S C|)-n+2$

\section{4) Behavioral Metrics}

The perspective of features contained in the ontology module and influencing behavior can be used to measure modular ontologies. Behavior of modular ontology can be measured through relationship and concept coverage, knowledge encapsulation, and depth of subsumption hierarchy. Concept coverage in this context, which is defined in [27], has a similar definition with Tartir's Inheritance Richness (IRs(M)) [30] of knowledge distribution within the module of ontology. Behavior quality (BQ) has dependency with those aspect mentioned, and the attributes defined as follows [27].

$$
B Q=w_{1} \times \text { KnowEncap }+w_{2}+I R_{\mathrm{s}}(M)+W_{3} \times D I T
$$

where

$w_{\mathrm{i}}$ are weights of corresponding behavioral metrics and total sum of weight $\left(\mathrm{w}_{\mathrm{i}}\right)$ is 1

Knowledge encapsulation is the means for ontology modules to hide their detailed

knowledge base and axioms, where

Knowledge Encapsulation (KnowEncap): $1-\frac{\sum_{j=1}^{n-1} \frac{\left|A x_{i j}\right|}{\left|A x_{i}\right|}}{n}$

Inheritance Richness (IRs(M)):

$$
I R_{S}(M)=\frac{\sum C_{1} \in C\left|H^{c}\left(C_{1}, C_{i}\right)\right|}{|C|} \text {, where }\left|H^{c}\left(C_{1}, C_{i}\right)\right| \text { represents the number of subclasses. }
$$

Depth in Tree/subsumption of hierarchy $(\mathrm{DIT})=\operatorname{Max}\left(\sum D\left|c_{i}\right|\right)$ where is the distance value of the path from the $i$ th child class of the ontology to Thing (Root) class.

5) Reliability

The reliability of the resulting ontology is determined by provenance. Provenance, $\mathrm{P}$, is an indirect measure obtained as a user-assigned score, where

$P=\rho / \rho_{\max }$

and $\rho$ is the rating given by users between 0 and $\rho_{\max }$.

\section{Methodology}

In the process of conducting this research, a framework called Methontology [31] has been applied in order to set a determined flow of TM Knowledge ontology development see Fig. 1. Ontology of TM Knowledge has been developed in another phase of this research [32], thus the focus of this discussion is mainly explain about the evaluation phase with respect to quality aspect. 


\section{A. Ontology Development}

TM knowledge ontology has been developed by using Protégé 5.2.0 in RDF format. The purpose is to increase the speed of executing query and loading the respective file for processing purpose [33].

In this paper [32], the TM knowledge ontology is developed by using traditional medical references from different sources in Indonesia region by adopting an approach from Indians Ayurvedic method [34]. In addition, this ontology has been developed and has passed the Methontology in planning and state phase.

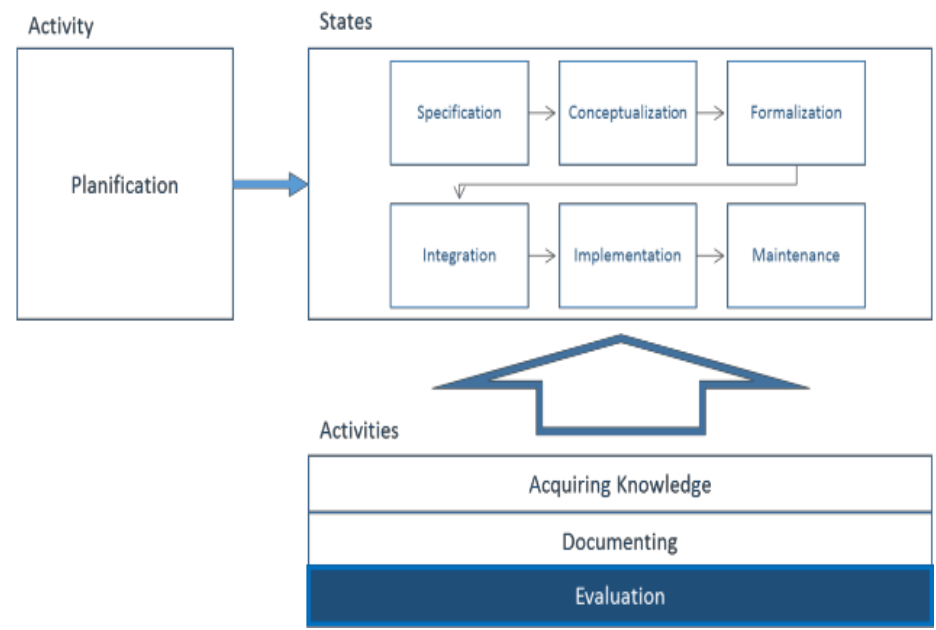

Figure 1. Evaluation in Methontology Framework [32]

\section{B. Ontology Quality Evaluation}

Since the quality measurement method for ontology is unclear, a number of methods for ontology modularization has been proposed recently. The objective of ontology evaluation is to prove its correctness and quality regarding to certain criteria and objectives [35]. In this research, we used evaluation and metrics namely OntoMod [27] and Tool for Ontology Module Metrics (TOMM) [28]. The quality measurement of this ontology allows analysis to identify areas that need to be improved, the parts that might have problems, and compare several ontologies for consideration.

TOMM has been validated experimentally to assess modular ontology [27, 28]. TOMM is a stand-alone Java application and can be downloaded from http://www.thezfiles.co.za/Modularity/TOMM.zip. The users of the application can upload an ontology module or set of related ontology modules. Then, TOMM calculates each metric of that module. As the result, the dependencies between the metrics of the modules and other dimensions of the framework can be ultimately revealed. The evaluation criterion of each parameter is specified within the TOMM experimental evaluation and conformity validation of OntoMod which help to analyse the result of measurement [27, 28]. Towards the evaluation phase, we apply the convention of TOMM evaluation metrics criterion stated as follows [28]:

Size, number of axioms, atomic size, intra-module distance, relative intra-module distance, attribute richness, and inheritance richness are measured on a numerical range.

Relative size, appropriateness, cohesion, encapsulation, coupling, and redundancy are measured on a 4-point scale of small (0-0.25), medium (0.25-0.5), moderate (0.51-0.75), and large (0.75$1)$. 


\section{Result Evaluations}

\section{A. Acquired Results}

A method of evaluation has been applied with respect to the TM Knowledge ontology through TOMM execution, i.e., by using the intended ontology in RDF format at the first place. As the result, we obtained the value for each parameter as described in the column of "Basic TOMM Result" [28] as shown in Table 1. The methods for ontology modules evaluation using TOMM are started with collecting ontology modules from evaluation files, executing TOMM metric tools for modules, and presenting statistical result of each module.

Table 1. Result Comparison after Analysis

\begin{tabular}{|l|c|c|}
\hline \multicolumn{1}{|c|}{ Parameters } & $\begin{array}{c}\text { Basic } \\
\text { TOMM }\end{array}$ & $\begin{array}{c}\text { Improved } \\
\text { Calculation }\end{array}$ \\
\hline No. of classes in ontology $|\mathrm{C}|$ & 40 & 40 \\
\hline No. of Object Properties in ontology & 73 & 73 \\
\hline No. of Data Properties in ontology $\mid \mathrm{DP}$ & 27 & 27 \\
\hline No. of Individual in ontology $|\mathrm{I}|$ & 427 & 427 \\
\hline SubClass of Axioms $\mid \mathrm{sc}$ & - & 39 \\
\hline Size of ontology $|\mathrm{M}|$ & 567 & 567 \\
\hline No. of axioms in ontology & 4497 & 4497 \\
\hline Appropriateness of ontology & -1.0 & 0.000355 \\
\hline Link density (LD) & - & 0.1282 \\
\hline Links per concept (LC) & - & 2.5 \\
\hline Link richness (LR) & - & 0.719 \\
\hline Cyclomatic Complexity (CC) & - & 101 \\
\hline ComplexOnto Score (ComplexOnto) & - & 26.0868 \\
\hline Cohesion of ontology & 0.07813 & 0.07813 \\
\hline Coupling of ontology & 0 & 0 \\
\hline Inheritance richness of ontology (IRS) & 3.0 & 3.0 \\
\hline Depth in subsumption of hierarchy (DIT) & - & 3.0 \\
\hline Encapsulation of ontology (KnowEncap) & 1.00 & 1.0 \\
\hline Behavior Quality (BQ) & - & 2.331 \\
\hline
\end{tabular}

Since the Java Application in TOMM has a limitation in providing the required parameters (i.e. DIT, BQ, etc.) for this evaluation, we attempted to add some improvements for the calculation in order to produce the expected values.

As the result, we successfully obtained the values that do not exist in the previous basic TOMM result and fixed the errors. The improved calculation column in Table 1 presents the acquired value after modifying its Java module and executing the improved TOMM Java application using ComplexOnto which align to this research objectives. Every representation of knowledge at a certain level of abstraction is judged by its ability by each ComplexOnto Metrics. The ontology editor can be used to calculate ComplexOnto Metric values based on independent variables contained in the structure of ontology graphs built on ontology artifacts.

\section{B. Analysis and Evaluation of The Results}

This section's purpose is to analyse the cause and the reason of the findings in the results and also to evaluate the suitability between the results and the purpose. Regarding to Table 1, there are some parameters that need to be discussed for analysis and evaluation of overall result which refer to Chapter II.C and is also described in the following explanation.

1. The size of the TM knowledge ontology in the Table 1 is 567. It shows that the value is larger than the optimal size of software module that had been defined in [36], where the optimum value is between 200-300. Since the TM knowledge ontology exists in one large ontology RDF file, it may be read as a single giant module. It brings a big impact when the ontology is in the state of unavailability since it is not created in a large number of modules. 
2. The appropriateness value, which indicates the defect density. This value is refined and recalculated using its formal definition from -1.0 to 0.000355 . The metrics defined in [35] has optimum value at 1 , where the range is lied between 0 to 1 . The huge number of the value's size indicates that the appropriateness is very small. In other words, this ontology is less appropriate according to the defined range.

3. The cohesion and coupling values are measured using the 4-point scale [28]. Basically, cohesion refers to the level of elements in the module or refers to the interrelationships in the members' functionality in an object-oriented software's class. Meanwhile, coupling is defined as the level of independence between modules: smaller interaction between modules indicates that the modules are declared as a detached coupling. Conversely, the high value of coupling is the result of tight interaction between modules. Good quality ontology modules should have low coupling value. According to Table 1, cohesion has small range where the interval consist of value between 0 to 0.25 Since those values are not negative and are in a small range, it can be shown that there are some ontology links that are so uncertain that they have a weak impact on cohesion and coupling.

4. The complexity of an ontology is measured qualitatively using the metrics defined in [37], where lower the number of complexities leads more likely to have a better quality of the ontology. The queries with high complexity need more response time than those with low complexity. Table 1 shows that the TM knowledge ontology has low rank of complexity due to its structure which consists of many individuals along with a number of axioms that are connected between them. Classes in an ontology's hierarchy with low complexity have more detailed information and specific and relevance meanings.

5. Evaluation of modular ontology is not enough to be accomplished from the structural point of view but also from the point of view of each feature that significantly influences its behaviour. The behavioural quality metrics applied in decreasing order (min. value is 1) which means that the lower of rank degree indicates a better quality of an ontology's behaviour [38]. According to Table 1, the value fall into the $B Q=[2,331]$. It shows that the behaviour of the TM knowledge ontology has a high degree of quality. Moreover, this behaviour is supported by the justification of each component in the BQ. The KnowEncap of TM knowledge ontology has optimal encapsulated knowledge truth value, which is ranged between 0 and 1 [38]. The IRs of TM knowledge ontology is measured relatively of the maximum value of subtree of the schema. This shows that the knowledge within the ontology is distributed vertically since the IRS value equals to the maximum depth of subclass $[38,39]$. Due to that, it also helps us measuring the depth that indicates the potential of its reusability, analysability, changeability, and testability [40]. Since the value of DIT is 3 , where it falls into the 4th criterion of SQuaRE range between 2 and 4, it explains that the TM knowledge ontology is acceptable and has a potential to be reused, analysed, changed, and tested.

\section{Future Works}

The results of the evaluation show that it is necessary for researchers to enhance the quality of the TM knowledge ontology in the next development cycle. There is a requirement to separate the ontology into several modules in order to enable a valid measurement and evaluation of intermodule distance, independency of a module, and redundancy of duplicate axioms. Moreover, calculation improvements are also required in the weight tuning and the number of ontology module evaluated at the same process. The minimization of unusual value gap between the acquired value and the average experiment value become important in the future in order to thus the value would have a minimum gap of error and build a better TM knowledge ontology.

\section{Conclusion}

The TM knowledge ontology is successfully evaluated in accordance to OntoMod and TOMM measurement and evaluation metrics. The evaluation result shows that the TM knowledge ontology requires some improvements in order to guarantee the good grade quality to be a reference of traditional medicine knowledge base. 


\section{Acknowledgment}

This research is financially supported by the Institut Teknologi Bandung (ITB) under Penelitian Terapan Unggulan Perguruan Tinggi (PTUPT) scheme.

\section{References}

[1]. W. M. Olatokun, "Indigenous knowledge of traditional medical practitioners in the treatment of sickle cell anemia," Indian Journal of Tradition Knowledge, vol. 9, no. 1, pp. 119-125, January 2010.

[2]. L. J. S. Tsuji and E. Ho, "Traditional Environmental Knowledge and Western Science: in Search of Common Ground," The Canadian Journal of Native Studies, vol. 2, no. 2, pp. 327-360, 2002.

[3]. K. Moran, Health: Indigenous Knowledge, Equitable Benefits, In Indigenous Knowledge (IK) Notes; No. 15. World Bank, Washington, DC. (C) World Bank. https://openknowledge.worldbank.org/handle/10986/10823 License: CC BY 3.0 IGO

[4]. P. Bagwana, "Indigenous Knowledge of Traditional Medicine: Answering the Question of Knowledge Acquisition and Transmission Among the Traditional Health Practitioners in Uganda." http://dergiler.ankara.edu.tr/dergiler/71/2037/21169.pdf.

[5]. A. S. Ramadianto, C. R. Andrian, M. Lenardi, R. Surya, W. Cheng, and F.N. Rahmawati, "Knowledge, Perception, and Attitude of Universitas Indonesia Medical Students toward Complementary and Alternative Medicine," J Asian Med Stud Assoc Original Research, vol. 4 no. 1, pp. 4-16, January 2015.

[6]. K. Chiwanza, M. C. C. Musingafi, and P. Mupa, "Challenges in Preserving Indigenous Knowledge Systems: Learning from Past Experiences," Information Knowledge Management, vol. 3, no. 2, pp. 19-26, 2013.

[7]. A. Rajendran and S. Rajan, "Indigenous knowledge: its role in the health care practices of the anamalai hills of Coimbatore district Tamil Nadu, India," Ancient Science of Life, vol. 18, no. 3-4, pp. 228-230, January 1999.

[8]. K. Dalkir, Knowledge Management in Theory and Practice, Elsevier Inc., 2005.

[9]. T. R. Gruber, "Toward principles for the design of ontologies used for knowledge sharing," International Journal of Human-Computer Studies, 43, 907-928, Dec. 1995. http://dx.doi.org/10.1006/ijhc.1995.1081

[10]. M. D. K. Rust, E. Mattheiss, C.M. Steiner, \& D. Albert, “A psycho-pedagogical framework for multiadaptive educational games," International Journal of Game-Based Learning, 1, 45-58. http://dx.doi.org/10.4018/IJGB

[11]. A. Zouaq, \& R. Nkambou, "Evaluating the generation of domain ontologies in the knowledge puzzle project," IEEE Transactions on Knowledge and Data Engineering, 21, 1559-1572, 2009. http://dx.doi.org/10.1109/TKDE.2009.25

[12]. N. Guarino, C.A. Welty, An Overview of OntoClean, in Handbook on Ontologies 2ed, 2009, pp. 201-220. ISBN 978-3-540-70999-2

[13]. L. Obrst, W. Ceusters, I. Mani, S. Ray, B. Smith, “The Evaluation of Ontologies,” In: Baker C.J.O., Cheung KH. (eds) Semantic Web. Springer, Boston, MA

[14]. Zhu, H., Liu, D., Bayley, I., Aldea, A., Yang, Y., Chen, Y.: Quality model and metrics of ontology for semantic descriptions of web services. Tsinghua Science \& Technology 22(3), 254-272 (2017)

[15]. M. Poveda-Villalon, A. Gomez-Perez, M.C. Suarez-Figueroa, "Oops! (Ontology pitfall scanner!): an on-line tool for ontology evaluation," International Journal Semantic Web Information Systems 10 (2) (2014) 7-34, 2014. DOI:10.4018/ijswis.2014040102

[16]. S. Tartir, I. Budak Arpinar, "Ontology evaluation and ranking using OntoQA," in: Proceeding International conference on semantic computing (ICSC 2007), IEEE, September 2007, pp. 185-192.

[17]. D. Vrandecic, Ontology Evaluation. Handbook on Ontologies, 2009, pp. 293-313 DOI:10.1007/978-3-540-92673-3_13 
[18]. K. M. Wiig, "Knowledge Management: An Introduction and Perspective," The Journal of Knowledge Management, vol. 1, no. 1, pp. 6-14, September 1997.

[19]. I. Nonaka, R. Toyama, and P. Byosiere, "Theory of Organizational Knowledge Creation: Understanding the Dynamic Process of Creating Knowledge," In: Dierkes, M.; et al. Handbook Organizational Learning and Knowledge. pp. 491-517, 2001. Oxford Univ. Press, Oxford, (2001)

[20]. D. Pears, What is Knowledge? ISBN-10: 0613158695 New York, NY, USA: Harper \& Row, 1971.

[21]. L. Greiner, Working with Indigenous Knowledge: A Guide for Researchers. International Development Research Centre, Canada, ISBN 0-88936-847-3, 1998.

[22]. K. Big-Canoe, "Indigenous Knowledge, Social Relationships and Health: CommunityBased Participatory Research with Anishinabe Youth at PIC River First Nation," Thesis, University of Western Ontario - London, ON, 2011.

[23]. W. Tungkwampian, A. Theerarungchaisri, and M. Buranarach, "Development of Thai herbal medicine knowledge base using ontology technique," The Thai Journal of Pharmaceutical Sciences, vol. 39, no. 3, pp. 102-109, 2015.

[24]. G. Atemezing and J. Pavon, “An Ontology for African Traditional Medicine”. International Symposium on Distributed Computing and Artificial Intelligence 2008 (DCAI'08): In Series: Advances in Intelligent and Soft Computing, Salamanca, Vol. 50, pp. 329-337 (2008)

[25]. D. W. Wardani, S. H. Yustianti, U. Salamah, and O. P. Astirin, “An Ontology of Indonesian Ethnomedicine", in International Conference on Information, Communication Technology and System, 2014, pp. 47-52.

[26]. L. Băjenaru, I. Smeureanu, A. Balog, An Ontology-Based E-Learning Framework for Healthcare Human Resource Management, Studies in Informatics and Control, ISSN 12201766, vol. 25(1), pp. 99-108, 2016. https://doi.org/10.24846/v25i1y201611

[27]. S. Kumar \& N. Baliyan, Semantic Web-Based Systems: Quality Assessment Models. eBook ISBN: 978-981-10-7700-5. Springer, 2018.

[28]. Z.C. Khan, C.M. Keet, "Dependencies Between Modularity Metrics Towards Improved Modules,” In: Blomqvist E., Ciancarini P., Poggi F., Vitali F. (eds) Knowledge Engineering and Knowledge Management. EKAW 2016. Lecture Notes in Computer Science, vol 10024. Springer, Cham

[29]. Z. Yang, D. Zhang, and C. Ye, "Evaluation metrics for ontology complexity and evolution analysis," in Proc. IEEE International Conference on e-Business Engineering (ICEBE'06).

[30]. S. Tartir, I.B. Arpinar, M. Moore, A.P. Sheth, \& B. Aleman-Meza, "OntoQA: Metric-Based Ontology Quality Analysis,” http://corescholar.libraries.wright.edu/knoesis/660

[31]. M.F. López, A.G. Pérez, and N. Juristo, "METHONTOLOGY: From Ontological Art Towards Ontological Engineering," In Proceeding AAAI-97 Spring Symposium Series, 2426 March 1997, vol. SS-97-06, pp. 33-40, Stanford University, EEUU.

[32]. L. P. Yulianti, "Ontology Development for Indigenous Knowledge Case Study: Drug and Treatment of Local Tribes in Indonesia", Master Thesis, in Bahasa, Institut Teknologi Bandung, Indonesia, 2018, unpublished.

[33]. Y. Guo, Z. Pan, and J. Heflin, "LUBM: A benchmark for OWL knowledge base systems," Journal of Web Semantics, vol. 3, no. 2-3, pp. 158-182, October 2005.

[34]. S. B. Kayne, "Introduction to traditional medicine," In: S.B. Kayne, Ed., Complementary and Alternative Medicine, 2nd Edition, Pharmaceutical Press, London, 2009, pp. 1-24.

[35]. Hlomani, H., Stacey, D.: Approaches, methods, metrics, measures, and subjectivity in ontology evaluation: a survey. Semant. Web J. 1-5 (2014).

[36]. A. Schlicht and H. Stuckenschmidt. Towards structural criteria for ontology modularization. In P. Haase, V. Honavar, O. Kutz, Y. Sure, and A. Tamilin, editors, 1st International Workshop on Modular Ontologies (WoMO'06), volume 232 of CEUR Workshop Proc. CEUR-WS.org, 2006. November 5, Athens, Georgia, USA. 
[37]. N. Baliyan \& S. Kumar (2014), "Software Process and Quality Evaluation for Semantic Web Applications," IETE Technical Review, 31:6, 452-462, DOI:10.1080/02564602.2014.967317.

[38]. N. Baliyan and S. Kumar, "A Behavioral Metrics Suite for Modular Ontologies," Proceeding Second International Conference on Information and Communication Technology for Competitive Strategies (ICTCS-2016)

[39].F. Ensan and W. Du, "Canadian Semantic Web: Technologies and Applications," Development, ISBN 978-1-4419-7334-4, Springer Science, 2010

[40]. A. Duque-Ramos, J. T. Fernandez-Breis, R. Stevens, and N. Aussenac-Gilles, "OQuaRE: A SQuaRE-based approach for evaluating the quality of ontologies," Journal of Research and Practice in Information Technology vol. 43, no. 2, pp. 159-173, 2011.

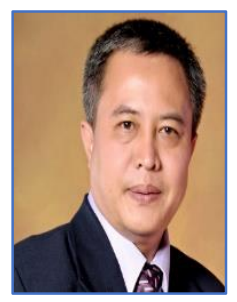

Kridanto Surendro received the $\mathrm{PhD}$ degree in Computer Science from Keio University, Japan, in 1999. He is currently working at Institut Teknologi Bandung, Indonesia. Surendro is working in the area of Information Systems, Information \& Knowledge Analytic, and Information Governance. His Research Interests include the Application of Artificial Intelligence to Enterprise Engineering.

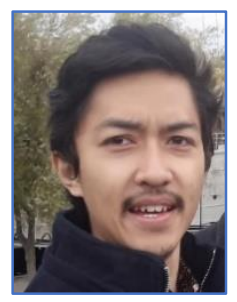

Farrell Yodihartomo received the bachelor degree in Information Systems and Technology form Institut Teknologi Bandung in 2015. He is currently studying master's degree in information system at Uppsala University, Sweden.

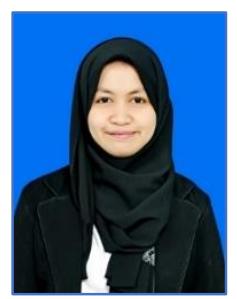

Lenny Putri Yulianti was born in Padang, Indonesia in 1996. She received B.Sc. in Information System and Technology from Institut Teknologi Bandung (ITB) in 2017 and M.Sc. in Informatics from ITB in 2018. Since 2019, She is a Lecturer at School of Electrical Engineering and Informatics ITB, Indonesia. Her current research Interests are Information System, Ontology, and Interaction Design. 